\title{
Nuclear Genetic Defects of Mitochondrial ATP Synthase
}

\author{
K. HEJZLAROVÁ ${ }^{1}$, T. MRÁČEK ${ }^{1}$, M. VRBACKÝ ${ }^{1}$, V. KAPLANOVÁ ${ }^{1}$, V. KARBANOVÁ ${ }^{1}$ \\ H. NƯSKOVÁ ${ }^{1}$, P. PECINA ${ }^{1}$, J. HOUŠTĚK ${ }^{1}$
}

${ }^{1}$ Department of Bioenergetics, Institute of Physiology Academy of Sciences of the Czech Republic, Prague, Czech Republic

Received August 16, 2013

Accepted August 30, 2013

\section{Summary}

Disorders of ATP synthase, the key enzyme of mitochondrial energy provision belong to the most severe metabolic diseases presenting as early-onset mitochondrial encephalocardiomyopathies. Up to now, mutations in four nuclear genes were associated with isolated deficiency of ATP synthase. Two of them, ATP5A1 and ATP5E encode enzyme's structural subunits a and $\varepsilon$, respectively, while the other two ATPAF2 and TMEMTO encode specific ancillary factors that facilitate the biogenesis of ATP synthase. All these defects share a similar biochemical phenotype with pronounced decrease in the content of fully assembled and functional ATP synthase complex. However, substantial differences can be found in their frequency, molecular mechanism of pathogenesis, clinical manifestation as well as the course of the disease progression. While for TMEM70 the number of reported patients as well as spectrum of the mutations is steadily increasing, mutations in ATP5A1, ATP5E and ATPAF2 genes are very rare. Apparently, TMEM7O gene is highly prone to mutagenesis and this type of a rare mitochondrial disease has a rather frequent incidence. Here we present overview of individual reported cases of nuclear mutations in ATP synthase and discuss, how their analysis can improve our understanding of the enzyme biogenesis.

\section{Key words}

Mitochondrial diseases • TMEM70 • ATPAF2 • ATP5A1 • ATP5E

\section{Corresponding author}

J. Houštěk, Institute of Physiology Academy of Sciences of the Czech Republic, v.v.i., Vídeňská 1083, 14220 Prague 4, Czech Republic. Fax: +420 24106 2149. E-mail: houstek@biomed.cas.cz

\section{Mitochondrial diseases}

As the mitochondrial oxidative phosphorylation (OXPHOS) system is the main source of ATP in mammalian cells, it is not surprising that insufficient mitochondrial energy provision can lead to the deleterious dysfunction of organs and tissues with high energy demands such as heart, muscle and brain manifesting as mitochondrial diseases (Dimauro 2011). These OXPHOS disorders belong to the most severe inborn metabolic diseases primarily affecting newborns and small children, with no causal therapy yet available. Understanding of the molecular mechanisms leading to the pathologies and development of future therapeutic strategies require the identification of the disease-causing genes. OXPHOS system is genetically unique, because 13 of approximately 100 polypeptides constituting respiratory chain complexes and ATP synthase are encoded by maternally transmitted mitochondrial DNA (mtDNA) of $16.6 \mathrm{~kb}$; the pathogenic mutations can therefore reside in both nuclear and mitochondrial genomes. The first described genetic defects of OXPHOS system were large deletions of mtDNA (Holt et al. 1988) and a point mutation in mtDNA MT-ND4 gene for subunit 4 of complex I, NADH dehydrogenase (Wallace et al. 1988). Identification and characterization of mtDNA mutations dominated molecular genetic studies of mitochondrial diseases in successive two decades and at present more than 200 point mutations and hundreds of deletions are listed in MITOMAP inventory (www.mitomap.org, Ruiz-Pesini et al. 2007). Bourgeron et al. (1995) reported the first defect in a nuclear gene

PHYSIOLOGICAL RESEARCH • ISSN 0862-8408 (print) • ISSN 1802-9973 (online)

(c) 2014 Institute of Physiology v.v.i., Academy of Sciences of the Czech Republic, Prague, Czech Republic

Fax +420 241062 164, e-mail: physres@biomed.cas.cz, www.biomed.cas.cz/physiolres 
resulting in a mitochondrial respiratory chain deficiency a mutation in SDHA gene affecting complex II, succinate dehydrogenase. As most of OXPHOS disorders are transmitted as autosomal recessive traits, the number of recognized nuclear disease-causing genes was growing rapidly and by 2001, nuclear genetic defects had been reported in all electron transporting complexes of mitochondrial respiratory chain (Shoubridge 2001). Since then, increasing interest in nuclear genes constituting mitochondrial proteome further stimulated progress in identification of affected nuclear genes encoding either structural proteins or biogenetic and regulatory factors of OXPHOS machinery - representing so called "direct and indirect hits" (Dimauro 2011). Today more than 150 nuclear genetic defects have already been associated with disorders of mitochondrial energetic machinery (Vafai and Mootha 2012). They include also four genes responsible for the deficiency of mitochondrial ATP synthase, the key enzyme of mammalian ATP production.

\section{ATP synthase structure and function}

Proton-translocating mitochondrial ATP synthase $\left(\mathrm{F}_{1} \mathrm{~F}_{\mathrm{o}}\right.$-ATPase, complex V, EC 3.6.3.14) is located in the inner mitochondrial membrane. It operates as a molecular motor utilizing proton motive force $\Delta p$ of proton gradient generated by respiratory chain for phosphorylation of ADP. ATP synthase complex of $\sim 600 \mathrm{kDa}$ is composed of
17 different subunits organized into membrane-extrinsic $F_{1}$ catalytic part and membrane-embedded $\mathrm{F}_{\mathrm{o}}$ part that are connected by two stalks (Walker 2013) (Fig. 1). Matrix oriented $F_{1}$ is formed by $\alpha_{3} \beta_{3}$ hexamer and by central stalk subunits $\gamma, \delta$ and $\varepsilon$. The stalk subunits attach the $F_{1}$ to subunit c-oligomer (c-ring), occupying about half of the $\mathrm{F}_{\mathrm{o}}$ moiety. The $\mathrm{F}_{\mathrm{o}}$ sector is further composed of subunits a, e, $\mathrm{f}, \mathrm{g}, \mathrm{A} 6 \mathrm{~L}$ and $\mathrm{b}$ subunit that extends to the matrix and together with the subunits $\mathrm{d}_{2} \mathrm{~F}_{6}$ and OSCP form the peripheral stalk connecting the $F_{0}$ part to $F_{1}$. As the protons pass at the interface of the subunit a and c-oligomer, the proton gradient powers rotation of the c-ring and the central stalk thus induces cyclic conformational changes in $\alpha_{3} \beta_{3}$ hexamer. Consequently, ADP and $\mathrm{P}_{\mathrm{i}}$ are bound and ATP synthesized and released through a cyclic bindingchange mechanism (Boyer 1975). The efficacy of the process stems from the number of protons translocated per one rotation of the c-oligomer as for each copy of the c subunit one proton is utilized. The most efficient of all is mammalian enzyme containing 8 subunits, while 10-15 subunits are found in yeast and bacterial enzymes (Walker 2013). Small regulatory subunit $I_{1}$ binds to $F_{1}$ at low $p H$ and prevents the enzyme from a switch to hydrolytic mode and ATP hydrolysis. Other proteins described to be associated with ATP synthase are membrane proteins DAPIT (Diabetes-Associated Protein in Insulin-sensitive Tissue) and $6.8 \mathrm{kDa}$ proteolipid (MLQ) (Chen et al. 2007, Meyer et al. 2007, Ohsakaya et al. 2011).

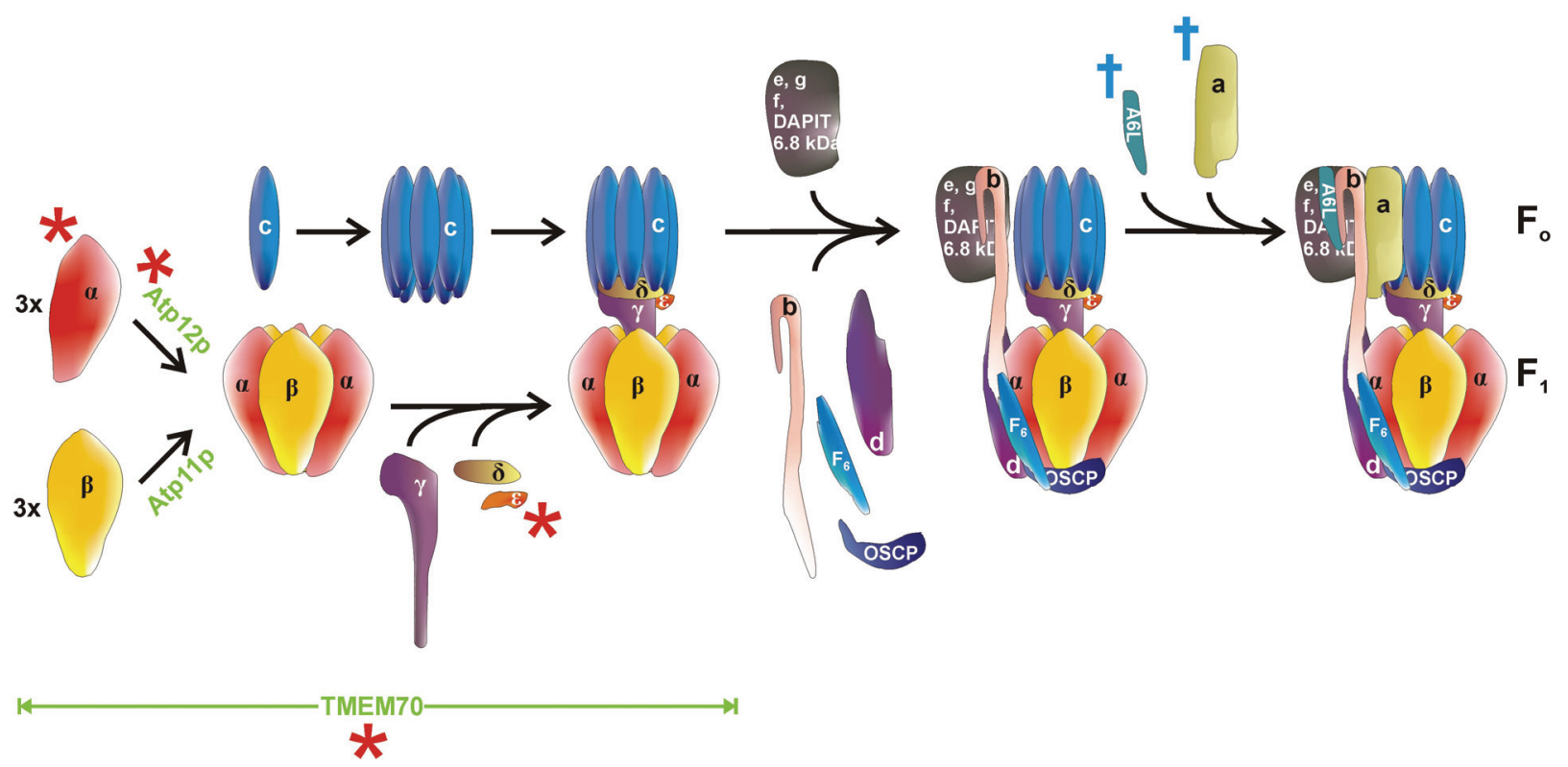

Fig. 1. Assembly scheme of mammalian ATP synthase. ATP synthase assembly starts with the $a_{3} \beta_{3}$ hexamer formation, then central stalk subunits $Y, \delta$ and $\varepsilon$ are added. The newly formed $F_{1}$ part is connected with the c-ring $\left(F_{1}+c\right.$ intermediate) and the assembly follows with subsequent addition of the $F_{0}$ part subunits and peripheral stalk subunits. In the last steps mtDNA-encoded subunits a and $\mathrm{A} 6 \mathrm{~L}$ are incorporated. Red asterisks mark nuclear-encoded structural subunits and enzyme-specific biogenetic factors, the mutations of which are responsible for isolated deficiency of ATP synthase; blue crosses mark structural subunits with mtDNA mutations. 


\section{Biogenesis of ATP synthase}

The biogenesis of ATP synthase is a very complex process that is still not fully understood. Current concept of the ATP synthase assembly is largely based on yeast model, $S$. cerevisiae, while the studies in mammalian cells are much less complex (see Ackerman and Tzagoloff 2005, Kucharczyk et al. 2009, Rak et al. 2009, 2011). Importantly, only subunits a (Atp6p) and A6L (Atp8p) are mtDNA-encoded in mammals, while in $S$. cerevisiae subunit c (Atp9p) is also mtDNA-encoded. The formation of ATP synthase from individual subunits is a stepwise procedure, proposed to proceed via assembly of several modules (Fig. 1), starting with an independent formation of $\mathrm{F}_{1}$ and oligomer of c-subunits. After the $F_{1}$ attaches to the membrane-embedded c-ring, the subunits of peripheral arm (consisting of subunits $b$, $\mathrm{d}, \mathrm{F}_{6}$ and OSCP) and of membranous subcomplex (consisting of subunits e, f, g, DAPIT and $6.8 \mathrm{kDa}$ protein) are added. In the last stage the enzyme structure is completed by incorporation of the two mtDNAencoded subunits, a and A6L (Wittig et al. 2010). Both initial and end-stage of enzyme assembly appear to be identical in yeast and mammals, while the intermediate steps in mammalian enzyme biogenesis are partly hypothetical.

The ATP synthase biogenesis is assisted by numerous, enzyme-specific factors that partly differ between lower and higher eukaryotes. In S. cerevisiae, where the $\mathrm{c}$ subunit is encoded by mtDNA, several yeastspecific factors (Nca1-3p, Nam1p, Aep1-3p, Atp22p and Atp25p) are involved in the $F_{o}$ biogenesis, namely in mRNA stability, translation and processing of mtDNA encoded subunits Atp6p and Atp9p (Tzagoloff et al. 2004, Ackerman and Tzagoloff 2005, Zeng et al. 2007a,b, 2008) or their assembly (Atp10p, Atp22p). However, none of them exists in mammals reflecting differences in structure of mitochondrial genes and expression of mtDNA-encoded subunits. Additional factor Atp23p (Osman et al. 2007, Zeng et al. 2007b) with metalloprotease/chaperone activity participates in processing of Atp6 $p$ and its association with c-oligomer, but there is only a partial homolog of Atp23p in mammals and its function remains unknown.

Assembly of the yeast $F_{1}$ part depends on three additional factors, Atp11p, Atp12p and Fmc1p (Ackerman and Tzagoloff 1990, 2005, LefebvreLegendre et al. 2001). Only the first two have their homologues in humans (Wang et al. 2001) interacting with the subunits $\beta$ and $\alpha$, respectively, during the $\alpha_{3} \beta_{3}$ hexamer formation (Fig. 1). Recently a $21 \mathrm{kDa}$ protein called TMEM70 was described as a new and specific ancillary factor of mammalian ATP synthase and its absence strongly inhibits the enzyme biosynthesis (Cizkova et al. 2008, Houstek et al. 2009).

The functional monomers of ATP synthase can further interact together and it has been shown that ATP synthase is organized as dimers and higher oligomers in different types of energy-transducing membranes, including yeast and mammalian mitochondria (see Wittig and Schagger 2008, 2009, Wittig et al. 2008, 2010). Interaction between two monomers occurs via $\mathrm{F}_{\mathrm{o}}$ and appears to involve subunits a, e, g, b and A6L. As the monomers interact in the dimers at $70-90^{\circ}$ angle and the neighboring dimers at $20^{\circ}$ angles, the supramolecular ATP synthase ribbons can shape the inner membrane at the apical regions and thus support cristae formation. Furthermore, this supramolecular organization could potentiate ATP synthesis and be functionally advantageous (Strauss et al. 2008).

\section{ATP synthase disorders due to mtDNA mutations}

Isolated disorders of ATP synthase manifest mostly as mitochondrial encephalo-cardiomyopathies, often severe with neonatal onset. However, as with other mitochondrial diseases, the spectrum of clinical phenotypes can be rather broad including mild and late manifestations (Schon et al. 2001, DiMauro 2004, Houstek et al. 2004, Jonckheere et al. 2012). Primary defects in the enzyme structure and function belong to two distinct groups depending on the affected genes. Maternally transmitted mtDNA mutations affect both mitochondrial-encoded subunits a and A6L. Here the function of $\mathrm{F}_{\mathrm{o}}$ proton channel, stability of ATP synthase complex and possibly enzyme-enzyme interactions can be altered. The structural impairment due to missense mutations or lack of the subunit is rarely accompanied by major changes in ATP synthase content. Biochemical and clinical phenotypes depend on mtDNA mutation load and majority of cases manifest only when a genetic threshold of $\sim 80-90 \%$ of mutated mtDNA copies is reached. The second group of ATP synthase disorders are autosomal recessive nuclear genetic defects. Mutations are found in several genes encoding structural subunits of enzyme or biogenetic-assembly factors and common biochemical phenotype of altered enzyme biogenesis is a low content 
of otherwise functional enzyme.

Nowadays, mtDNA mutations are routinely screened and relatively easily diagnosed. More than 30 different mutations in MT-ATP6 and MT-ATP8 genes have already been described (www.mitomap.org). The majority of them are MT-ATP6 missense mutations; single mutations are associated with severe brain, heart and muscle disorders with early-onset, but also with deafness, multiple sclerosis, autism, optic neuropathy or diabetes. The most common are $m .8993 T>G$ (p.L156R) or $m .8993 T>C$ (p.L156P) transitions, manifesting usually as milder NARP (Neurogenic muscle weakness, ataxia, and retinitis pigmentosa) or more severe MILS (Maternally inherited Leigh syndrome). In general, the severity of $T>G$ transition depends on the level of heteroplasmy, but other polymorphisms in the mtDNA as well as additional factors may also influence the disease pathology (Enns et al. 2006, D'Aurelio et al. 2010, Kara et al. 2012). $T>C$ transition is less common, symptoms are milder and with later onset (Morava et al. 2006, Baracca et al. 2007, Craig et al. 2007). Similar features were described in the other relatively common transitions, $m .9176 T>G$ (p.L217R) and m.9176T $>C$ (p.L217P) presenting as Leigh disease or Familial bilateral striatal necrosis (Carrozzo et al. 2001, Hung and Wang 2007, Vazquez-Memije et al. 2009). MT-ATP6 mutations may also associate with some multifactorial polygenic diseases. For example, the m.9176T $>C$ transition was found in late-onset hereditary spastic paraplegia (Verny et al. 2010) and m.9176T $>C$ or m.9185T>C transitions were harbored in patients with mild Charcot-Marie-Tooth hereditary neuropathy (Pitceathly et al. 2012, Synofzik et al. 2012).

While the above discussed MT-ATP6 transitions cause replacements of amino acids (AA) involved in the function of proton channel, a unique microdeletion of two base pairs at positions $9205 / 6$ (m.9205delTA) at the interface of MT-ATP6 and MT-CO3 genes (Seneca et al. 1996) alters the splicing and maturation of their mRNAs and down-regulates the synthesis of subunit a (Jesina et al. 2004). Mitochondrial content of ATP synthase is unaffected but the enzyme is non-functional, because the proton channel in the $\mathrm{F}_{\mathrm{o}}$ cannot operate in the absence of subunit a.

Mutations of MT-ATP8 gene are a rarer cause of mitochondrial encephalo-cardiomyopathies. The $m .8529 G>A$ nonsense mutation was found in a patient with hypertrophic cardiomyopathy and neuropathy. ATP synthase complex was destabilized, which led to the strong reduction in holoenzyme content and accumulation of $\mathrm{F}_{1}$ subcomplexes (Jonckheere et al. 2008). Later on, m.8411A $>G$ missense mutation (p.M16V) in the conserved region of $\mathrm{A} 6 \mathrm{~L}$ protein in a patient with severe mitochondrial disorder (Mkaouar-Rebai et al. 2010) and $m .8528 T>C$ mutation changing conserved tryptophan 55 to arginine in $\mathrm{A} 6 \mathrm{~L}$ subunit as well as MT-ATP6 initiation codon of subunit a in a patient with infantile hypertrophic cardiomyopathy (Ware et al. 2009) were reported.

\section{Nuclear genetic defects}

At present, inborn and isolated disorders of ATP synthase are associated with four nuclear genes, two of which code for the structural subunits $\alpha$ and $\varepsilon$ while the other two encode biogenetic factors Atp12p and TMEM70 that are not part of the enzyme structure. All these mutations share a similar biochemical phenotype with pronounced decrease in the content of fully assembled and functional ATP synthase. However, their incidences, mechanism of molecular pathogenesis, clinical manifestation, as well as the course of the disease progression, differ substantially. Up to now, only two patients with mutations in ATP5A1 and one patient each with mutations in ATP5E and ATPAF2 genes were reported pointing to the level of rareness of these disorders. In contrast, nearly 50 cases of diagnosed patients with mutation in TMEM70 gene have already been described and the number of reported patients and affected families as well as the spectrum of TMEM70 mutations is steadily increasing. Apparently TMEM70 gene is highly prone to mutagenesis and this type of rare mitochondrial disease has relatively frequent incidence.

\section{Mutations in ATP synthase biogenetic factors}

The first indication that ATP synthase dysfunction could be linked to a nuclear gene came from the study of Holme et al. (1992) who were unable to find any mtDNA mutation in a child with cardiomyopathy, lactic acidosis, persisting 3-methylglutaconic aciduria (3-MGA) and severely decreased activity of ATP synthase. Seven years later in another patient, we have demonstrated by the use of mitochondrial cybrids that mitochondrial disease presenting as early onset neonatal and fatal lactic acidosis, cardiomyopathy and hepatomegaly due to a $70 \%$ isolated decrease of ATP synthase complex was of nuclear origin (Houstek et al. 1999). A number of similar patients have been described (Sperl et al. 2006) due to a joint effort of several 
European mitochondrial centers that focus specifically on putative disorders of ATP synthase. DNA sequencing of those patients excluded mutations in genes for structural subunits, but De Meirleir et al. (2004) described one patient with severe neonatal encephalopathy who harbored missense mutation in Atp $12 \mathrm{p}$ protein, an assembly factor essential for incorporation of $\alpha$ subunit into $F_{1}$-ATPase structure. Four years later, we used the homozygosity mapping and sequencing of candidate genes in other known patients and identified TMEM70 as another disease-causing gene. The splicing site mutation in the second intron preventing the synthesis of TMEM70 protein was found in 24 cases including the first patient reported in 1999 (Cizkova et al. 2008, Honzik et al. 2010).

\section{ATPAF2 mutation disease}

A homozygous c.280T $>A$ mutation in $A T P A F 2$ gene coding for Atp12p was discovered in a girl with dysmorphic features, cortical-subcortical brain atrophy followed by basal ganglia atrophy and metabolic acidosis, who died at the age of 14 months (De Meirleir et al. 2004). Activity and specific content of ATP synthase was strongly decreased, liver tissue was more affected than skeletal muscle. In liver mitochondria, severe reduction in native complex $\mathrm{V}$ without accumulation of $\mathrm{F}_{1}$ containing subcomplexes was discovered. Significantly reduced content of individual ATP synthase subunits suggested that $\mathrm{F}_{1}$ assembly could be disturbed at the early stage and the unassembled subunits were rapidly degraded. The $T G G>A G G$ transition caused replacement of evolutionary conserved neutral tryptophan in position 94 to a basic arginine (p.W94R), probably affecting the Atp12p interaction with $\alpha$ subunit. Both parents (consanguineous, Moroccan origin) and unaffected sibling were heterozygous carriers of the mutation. With the help of a yeast model, it was later shown that this mutation affects the solubility of Atp12p protein, with the mutated form showing tendency to aggregate (Meulemans et al. 2010).

\section{TMEM70 mutation disease}

A search for affected nuclear gene in a large group of patients with ATP synthase deficiency, severe neonatal lactic acidosis and encephalo-cardiomyopathy led to the identification of $c .317-2 A>G$ mutation at the end of the second intron of TMEM70 gene as a cause of the mitochondrial disease (Cizkova et al. 2008). Their fibroblasts showed decreased ADP-stimulated respiration, low ATP synthase activities and significantly reduced levels of fully assembled complex $\mathrm{V}$ with increased content of $F_{1}$ subcomplexes. All structural and functional changes in patient fibroblasts were complemented after transfection with wild type TMEM70 (Fig. 2). As the defect affected assembly of the enzyme, TMEM70 was recognized as a new biogenetic factor of ATP synthase.

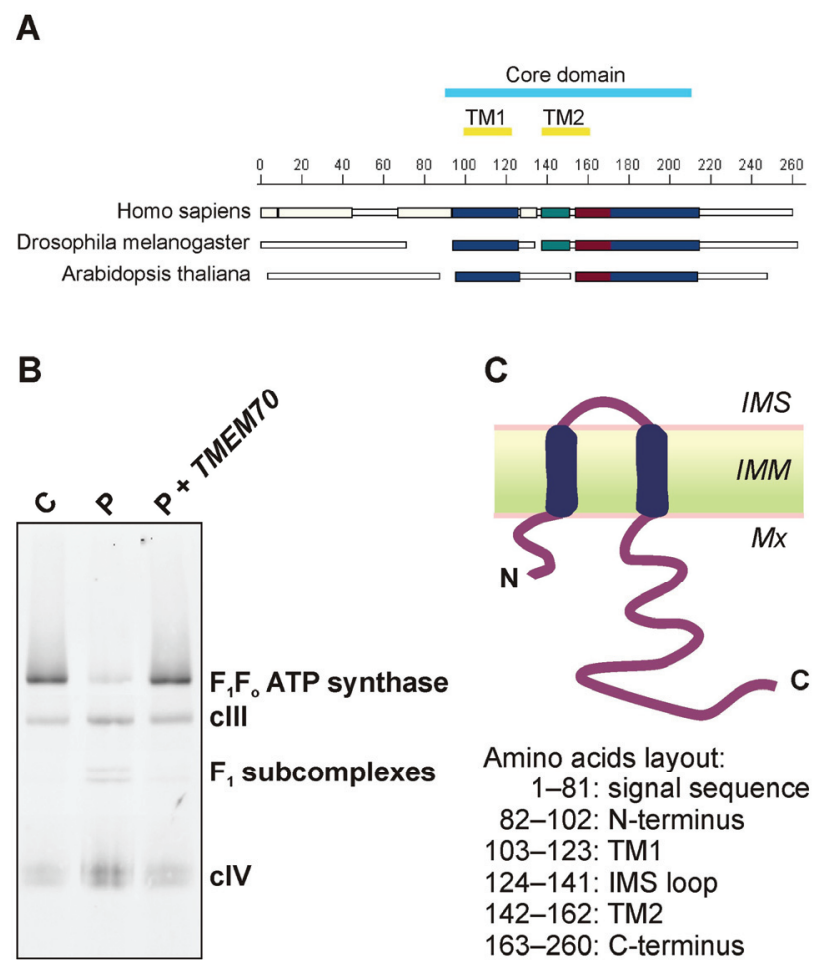

Fig. 2. Structure of TMEM70 protein and TMEMTO complementation of ATP synthase deficiency. A. Sequence alignment of TMEM70 protein. Color of the boxes indicates the level of homology between different organisms (red, blue, green, and white; from the most homologous to the least, respectively). TM1, TM2 denote putative transmembrane regions. Core domain represents central, the most homologous part of the protein. B. Decrease of assembled ATP synthase $\left(F_{1} F_{0}\right.$ ATP synthase) and accumulation of $F_{1}$ subcomplexes in patient fibroblasts with TMEM70 mutation $(P)$ are reversed by complementation with wild type TMEMTO (P+TMEM7O); control cells (C); cIII and cIV are signals of respiratory chain complexes. C. Structure and orientation of mature TMEM70 protein in the inner mitochondrial membrane (IMM); the intermembrane space (IMS); the matrix (Mx).

TMEM70 - a novel ancillary factor of ATP synthase biogenesis

Mitochondrial localization of TMEM70 protein was first described by Calvo et al. (2006), later it was included in Mitocarta inventory (www.broadinstitute.org/pubs/MitoCarta/), the database of proteins most likely constituting human and mouse mitochondrial proteome (Pagliarini et al. 2008). TMEM70 gene is located on chromosome 8, consists of 
three exons and encodes a 260 amino acids protein that contains a conserved DUF1301 domain and two putative transmembrane regions indicating membrane-association of the protein (Fig. 2A). Analysis of human TMEM70 precursor protein of $30 \mathrm{kDa}$ showed, that it is imported into mitochondria and upon removal of $9 \mathrm{kDa} \mathrm{N}$-terminal signal sequence it is processed to $21 \mathrm{kDa}$ mature TMEM70 protein, localized in the inner mitochondrial membrane (Hejzlarova et al. 2011). As predicted from the amino acid sequence, it contains two short transmembrane domains, $21 \mathrm{AA}$ each, separated by even shorter 18 AA connecting sequence suggesting a hairpin like transmembrane fold of the protein (Fig. 2C). Short N-terminal (21 AA) and long C-terminal (98 AA) sequences of the mature protein should then be exposed to the same hydrophilic compartment. Their orientation was predicted to be towards the mitochondrial matrix (Jonckheere et al. 2011) and our recent studies with tagged forms of TMEM70 protein confirm this prediction (Kratochvilova et al., in preparation).

The biological role of TMEM70 protein is directly linked to the biogenesis of ATP synthase but its exact function is not yet known. TMEM70 facilitates the formation of ATP synthase complex, but it may proceed, albeit at a low intensity, even in the absence of TMEM70 protein, as small, yet still significant, amounts of functional ATP synthase are found in all patients. The low content of ATP synthase complex in the TMEM70-deficient cells is accompanied by the severely reduced content of individual subunits including subunit $\mathrm{c}$, suggesting fast degradation of unassembled subunits. Our previous studies indicated functional involvement of TMEM70 in the early stages of ATP synthase assembly (Houstek et al. 1999). Recently, Torraco et al. (2012) proposed the role of TMEM70 in stabilization of $F_{1}$ thus assisting further steps of enzyme biogenesis including the ultimate incorporation of the mtDNA encoded subunits a and A6L.

Transcript levels as well as protein detection by mass spectrometric analysis revealed very low abundance of TMEM70 protein, similar to the other ancillary factors (Hejzlarova et al. 2011). Detergent-solubilized protein resolved by Blue Native electrophoresis can be detected as a dimer or larger oligomers but its interacting partner(s) remain unknown. Genomic analysis found TMEM70 homologues in genomes of all multicellular eukaryotes and plants, but only in some yeast or fungi a considerable homology was found in the transmembrane regions but not in $\mathrm{N}$ - and $\mathrm{C}$-terminal regions (Cizkova et al. 2008, Jonckheere et al. 2011). Importantly,
S. cerevisiae, the main yeast model for studies of mitochondrial ATP synthase biogenesis lacks TMEM70 gene. Therefore, while more than a dozen of ATP synthase-specific biogenetic factors exist in yeast and are absent in mammals, TMEM70 protein is the first ancillary factor of mammalian ATP synthase that is, in contrary, absent in S. cerevisiae.

\section{Pathogenic mutations of TMEM70 gene}

Analysis of mutations in affected patients represents an important step towards better understanding of TMEM70 involvement in the biogenetic mechanism. Within the last couple of years, numerous other TMEM70 mutations have been described with a broad spectrum of phenotypes (Table 1). TMEM70 mutations associated with isolated ATP synthase deficiency are either homozygous or compound heterozygous, parents and healthy siblings of the patients are usually heterozygous carriers of the respective mutation(s).

The most common is the originally described homozygous c.317- $2 A>G$ mutation that removes the splicing site prior to the third exon and results in the generation of multiple incomplete and labile transcripts preventing synthesis of the protein. It has already been found in 30 patients (Cizkova et al. 2008, Wortmann et al. 2009, Honzik et al. 2010, Tort et al. 2011, Torraco et al. 2012, Stojanovic and Doronjski 2013) and other cases are known but have not been formally reported. Absence of TMEM70 protein in homozygous patients typically presents as early-onset and severe lactic acidosis, 3-MGA, hypertrophic cardiomyopathy, dysmorphism, hypotonia, ataxia, failure to thrive and psychomotor retardation. Out of 23 cases reported in 2008, about half died within the first few years and mostly in the first months of life. On the other hand some patients can survive significantly longer, with two of them currently reaching 12 and 17 years. As pointed out by a detailed retrospective clinical study (Honzik et al. 2010), if the patient survives the critical postnatal period of the first weeks and months of life, the metabolic problems and cardiac disorders may improve. Till now, only one patient was reported with rather late disease manifestation at the age of 3 years as a mild form of 3-MGA without hyperammonemia during the metabolic crisis (Stojanovic and Doronjski 2013). With one exception (Tort et al. 2011) the patients with homozygous c.317- $2 A>G$ mutation were of Roma origin but from several unrelated families (Wortmann et al. 2009, Honzik et al. 2010, Torraco et al. 2012, Stojanovic and Doronjski 2013). 


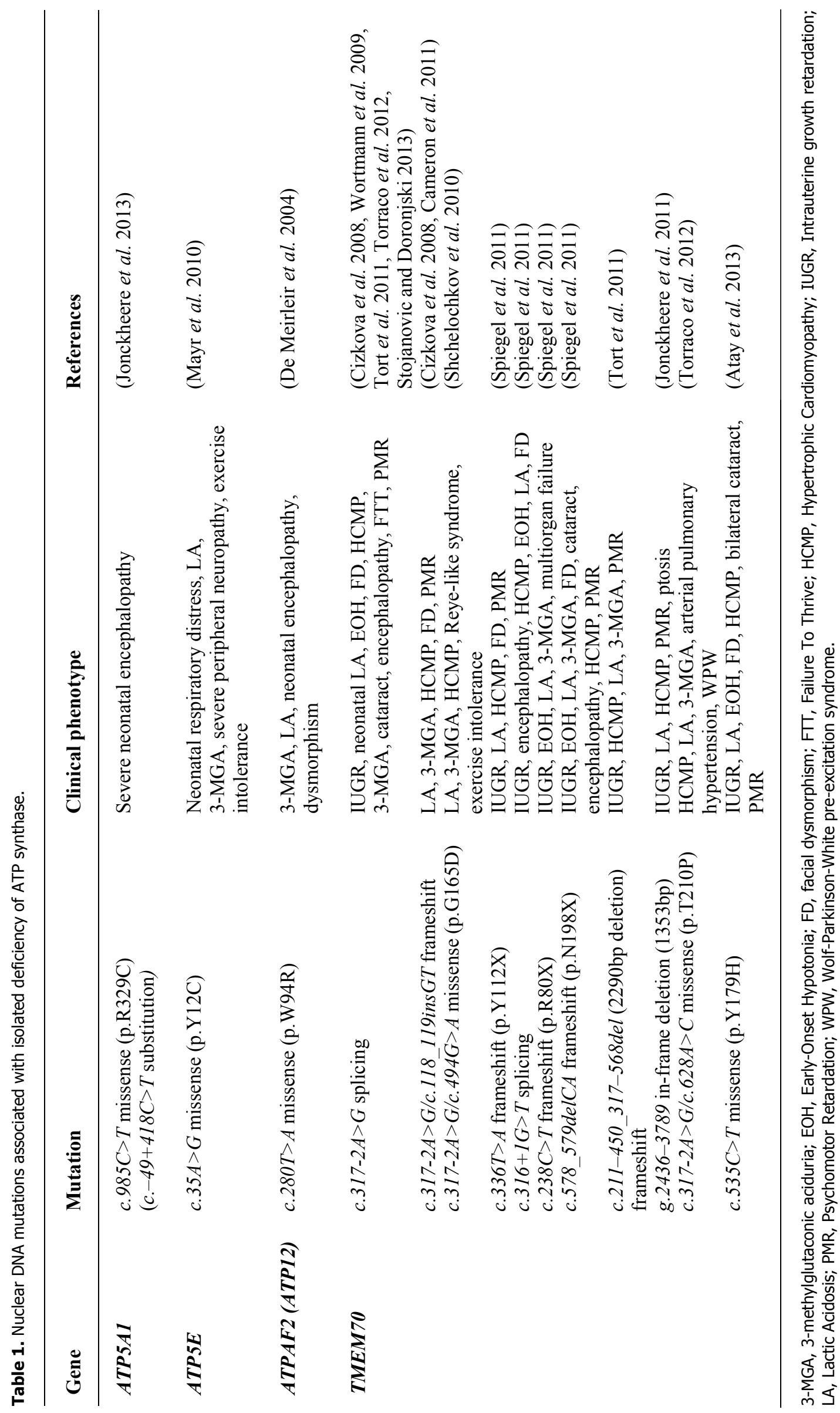


Another homozygous splicing site mutation c. $316+1 G>T$ was reported in two patients from Arab Muslim family (Spiegel et al. 2011). Would the resulting transcript devoid of exon 2 be translated, the aberrant TMEM70 protein lacked $34 \mathrm{AA}$ in the region 71-105, including last $10 \mathrm{AA}$ of the mitochondrial signal sequence and first $3 \mathrm{AA}$ of the first transmembrane domain. The consequence of this mutation could be inefficient import of TMEM70 into mitochondria or defective membrane assembly. The patients, two siblings of consanguineous parents presented with typical features described above but without 3-MGA and they died after 10 days and 5 months, respectively.

Different type of TMEM70 mutation, homozygous g.2436-3789 in-frame deletion resulting also in TMEM70 transcript lacking exon 2 was described in one child of Iraqi consanguineous parents (Jonckheere et al. 2011). Contrary to $c .316+1 G>T$ patients, this patient with psychomotor retardation survives much longer; he was reported at the age of 6 years.

Four additional homozygous frameshift mutations creating premature stop codon and leading to the synthesis of potentially truncated TMEM70 have been reported. Two Arab Muslim patients (siblings) with symptoms similar to other TMEM70 patients plus bilateral cataract harbored c.578_579delCA deletion resulting in a putative 197 AA long protein lacking almost two third of the C-terminus. Surprisingly, their survival is remarkably different; one is 24 years old while the second died at 3.5 years. TMEM70 mutation c.336T $>A$ was found in another Arab Muslim patient, and it predicts synthesis of a 112 AA long TMEM70 protein (Spiegel et al. 2011) while c.211-450_317-568del mutation deleting the whole exon 2 (Tort et al. 2011) would result in a protein only $71 \mathrm{AA}$ long that may be unstable and mislocalized. Both patients presented with hypertrophic cardiomyopathy, metabolic acidosis, mental retardation and facial dysmorphism at the age of 1 and 7 years, respectively. The last frameshift mutation c. $238 C>T$ resulting in a putative 80 AA long TMEM70 protein had severe phenotype with encephalopathy, hypotonia, metabolic acidosis and this Arab Muslim patient died 7 days old (Spiegel et al. 2011). All the patients reported by Spiegel et al. (2011) were from consanguineous families. The malfunction of the three short variants of TMEM70 protein is not surprising as even the longest (112 AA) only reaches till the first half of the first transmembrane domain.

The common $c .317-2 A>G$ mutation can also be found as compound heterozygous in combination with other TMEM70 mutations. Two patients were described carrying c.317-2A>G and c.118_119insGT frameshift mutation resulting in premature stop codon and putative TMEM70 protein of 40 AA (Cizkova et al. 2008, Cameron et al. 2011). In one case the mother is Italian carrying the common splicing mutation and the father is Croatian carrying the insertion (Cameron et al. 2011). Both patients show typical TMEM70 symptoms and they are alive. Another three patients have a combination of c. $317-2 A>G$ with a missense mutations, such as c. $494 G>A$ changing neutral glycine 165 to acidic aspartate at the C-terminus (Shchelochkov et al. 2010) or c. $628 A>G$ changing highly conserved threonin 210 to prolin (Torraco et al. 2012). The clinical outcome of North European origin patient reported by Shchelochkov et al. (2010) and presenting as Reye-like syndrome was mild, while both Italian patients reported by Torraco et al. (2012) are strongly affected; in addition to metabolic acidosis and cardiomyopathy Wolf-Parkinson-White preexcitation syndrome was found.

The only homozygous missense mutation described so far is $c .535 C>T$ mutation, which changes the highly conserved tyrosine to a histidine at position 179 at the beginning of the C-terminus (Atay et al. 2013). The patient of Turkish origin presented with cardiomyopathy, hypotonia, mild mental retardation, dysmorphism and bilateral cataract.

Although the changes in the quantity and structure of TMEM70 protein were not specifically addressed in most of the case reports, from the described mutations it appears that most of the genetic defects lead to the absence of this factor or the synthesis of incomplete truncated forms, lacking either a part of import sequence or a major part of the second transmembrane domain and/or C-terminal sequence. The p.Y179H amino acid replacement would point to a functional importance of conserved tyrosine at the beginning of the C-terminal sequence. A combination of splicing site and missense mutation could lead to the synthesis of sole TMEM70 protein with amino acid replacement if the splice variant mRNA was unstable and degraded. Interestingly, both such missense mutations, p.G165D and p.T210P affect the Cterminal region of the protein.

\section{Mutations in ATP synthase structural subunits}

It was not unexpected that isolated ATP synthase 
deficiency, similarly as isolated disorders of other OXPHOS complexes can also be caused by a "direct hit". In 2008 our search for mutated gene in 25 patients with ATP synthase deficiency revealed TMEM70 mutation in all but one patient (Cizkova et al. 2008) who also differed by a rather mild and distinct phenotype (Sperl et al. 2006). Subsequent sequencing of ATP synthase genes detected a mutation in $\varepsilon$ subunit of $F_{1}$ part as the first mutation in nuclear-encoded subunit of the enzyme (Mayr et al. 2010). Three years later mutation in another structural subunit of $F_{1}$ was discovered, in this case affecting ATP5Al gene, coding for the $\alpha$ subunit (Jonckheere et al. 2013).

\section{ATP5E mutation disease}

A nuclear mutation affecting $\varepsilon$ subunit of ATP synthase was found in 22 years old patient. Clinical phenotype started with early-onset lactic acidosis, 3-MGA, but no cardiac involvement, followed by mild mental retardation, exercise intolerance and peripheral neuropathy. Sequencing of $A T P 5 E$ gene coding for subunit $\varepsilon$ (Mayr et al. 2010) uncovered homozygous missense mutation c. $35 A>G$ replacing highly conserved tyrosine 12 with cysteine. Parents were healthy heterozygous carriers. In the patient fibroblasts decreased activities of ATP synthase and ADP-stimulated respiration with increased mitochondrial membrane potential at state 3-ADP were found, indicating an insufficient capacity of ATP synthase. The contents of both ATP synthase subunits and of fully assembled complex V were severely reduced. Surprisingly, the mutated subunit $\varepsilon$ depressed biosynthesis of ATP synthase but it was incorporated in the enzyme complex without altering its synthetic and hydrolytic functions. The reduction of assembled $600 \mathrm{kDa}$ complex $\mathrm{V}$ was not accompanied by the presence of $F_{1}$ subcomplexes. In the patient fibroblasts all enzyme subunits were correspondingly reduced with the exception of subunit $\mathrm{c}$, which was not degraded. When ATP5E was knocked-down in HEK293 cells (Havlickova et al. 2010) a similar phenotype was found - isolated decrease of fully functional ATP synthase complex corresponding to the low levels of subunit $\varepsilon$ and accumulation of subunit $c$. Changes in ATP synthase structure and function due to the mutation and downregulation of $\varepsilon$ subunit therefore indicated an essential role of $\varepsilon$ subunit in the biosynthesis and assembly of the $\mathrm{F}_{1}$ part of ATP synthase. Moreover, $\varepsilon$ subunit seems to be involved in the incorporation of subunit $\mathrm{c}$ into the rotor structure of the mammalian enzyme.

\section{ATP5A1 mutation disease}

Most recently, the first mutation was found in ATP 5A1 structural gene for subunit $\alpha$ in two siblings of non-consanguineous parents presenting with severe neonatal encephalopathy (Jonckheere et al. 2013). Both patients died at the first week of life and extensive damage of brain structures was accompanied by multiorgan lesions indicative of mitochondrial disease. Fibroblasts of both patients showed decreased oxygen consumption with unusually high activation by an uncoupler and isolated defect in ATP synthase hydrolytic activity. Strong reduction in specific content of fully assembled complex $\mathrm{V}$ without $\mathrm{F}_{1}$ subcomplexes accumulation was accompanied by the reduced levels of individual ATP synthase subunits. In both siblings exome sequencing detected heterozygous $c .985 C>T$ mutation in ATP5A1 gene that changed conserved basic arginine to neutral cysteine at position 329. The arginine 329 is predicted to be involved in the interaction between $\alpha$ and $\beta$ subunits, thus $\operatorname{Arg}>C y$ replacement can destabilize the $\alpha_{3} \beta_{3}$ hexamer. Observed missense mutation in subunit $\alpha$ indicates defect in the early stage of $\mathrm{F}_{1}$-ATPase assembly when $\alpha_{3} \beta_{3}$ hexamer is formed. ATP5A1 mutation revealed remarkable genetics. Healthy father was heterozygous carrier for the mutation, while mother expressed only the wild type sequence. Extensive analyses of the sequences and mRNA expression of ATP5A1 alleles of both parents suggested that the maternal allele was inherited by both affected children but its expression was inhibited. Therefore the pathogenic phenotype was dominated by the paternal mutated allele. The reason for altered expression of the maternal allele remains unknown. The only polymorphism found was $c .-49+418 C>T$ variant in the first intron, approximately $5.4 \mathrm{~kb}$ from the core promoter of ATP5A1 gene but there is no indication that it could affect the gene regulation.

\section{Pathogenic mechanism of ATP synthase deficiency}

Isolated defects of ATP synthase due to mutations in nuclear genes reported so far indicate that primarily affected is the initial stage of enzyme biosynthesis, i.e. the formation of $F_{1}$ part (Fig. 1) and the tissue content of the whole ATP synthase complex becomes reduced as a consequence. Despite different molecular genetic defects, in all these cases the mitochondrial pathology stems from the low content of ATP synthase in comparison to respiratory chain 
complexes. Such decrease in relative ATP synthetic capacity is expected to limit mitochondrial ATP production in vivo depending on the extent of enzyme defect. In most patients the deficiencies are rather pronounced, ranging from $60-70 \%$ decrease to a practically nondetectable levels of ATP synthase complex. Although this may reflect some methodological problems and differences in enzyme detection, it is clear that even relatively extreme defects can be tolerated to some extent, at least in terms of organs pathology and/or patients survival. Phenotypic manifestation of the genetic defects of OXPHOS system occurs only when a threshold level for a given reaction is exceeded (Rossignol et al. 2003). Physiological spare capacity of ATP synthase relative to respiratory chain enzymes was studied in detail in mouse tissues and demonstrated that for example in muscle, $80 \%$ inhibition of ATP synthase still allowed for almost normal state 3-ADP respiration (Rossignol et al. 1999). Analogous studies do not exist for human tissues and most of the functional data from patients are obtained in cultured cells. Nevertheless, this may be the key explanation why mitochondrial energy provision in nuclear genetic defects of ATP synthase is less affected than would be predicted from the decrease in enzyme content.

The low capacity of ATP synthase subsequently leads to elevated levels of mitochondrial membrane potential $(\Delta \Psi)$ at conditions of intensive coupled respiration, as demonstrated in TMEM70 and ATP5E mutated fibroblasts (Cizkova et al. 2008, Mayr et al. 2010). The high levels of $\Delta \Psi$ in respiring mitochondria stimulate the electron leak within the respiratory chain thus increasing the generation of reactive oxygen species (ROS). This has been demonstrated in TMEM70-lacking fibroblasts (Houstek et al. 2004, Mracek et al. 2006) and upregulation of ROS also altered fibroblast viability in glucose-free, pyruvate-containing medium. Thus ATP synthase deficiency is connected with both altered energy provision and enhanced oxidative stress, similarly as dysfunction of ATP synthase due to mtDNA MT-ATP6 mutations (Mattiazzi et al. 2004).

Mitochondrial biogenesis is subject of complex transcriptional regulation via $\mathrm{PGCl} / \mathrm{NRF}$ axis and it is expected that mitochondria-nucleus retrograde signaling could respond to a metabolic disbalance due to complex $\mathrm{V}$ deficiency. In fibroblast cell lines with identical TMEM70 homozygous $c .317-2 A>G$ mutation the decrease in complex $\mathrm{V}$ was accompanied by upregulation of respiratory chain complexes III and IV
(Havlickova Karbanova et al. 2012) and similar upregulation was also found in patient tissues (Mayr et al. 2004). These compensatory adaptive changes were not connected with upregulation of mRNAs for corresponding structural subunits or biogenetic factors pointing to posttranscriptional regulatory events. Interestingly, analogous increase in electron transport complexes was also present in fibroblasts of ATP5E patient (Mayr et al. 2010), although these changes apparently cannot improve the energetic dysfunction of complex V-lacking mitochondria.

Morphological changes in structure of mitochondria also represent an important aspect of ATP synthase deficiency. The role of ATP synthase dimers in mitochondria cristae formation was described in yeast models, where a downregulation of ATP synthase (Lefebvre-Legendre et al. 2005) or altered formation of ATP synthase dimers due to deficiency of the subunits e or g (Paumard et al. 2002) led to the absence of cristae and mitochondrial appearance as onion-like structures. Analogous morphological changes, concentric arrangement of mitochondrial cristae were observed in skeletal muscle mitochondria of a patient with TMEM70 c.317-2A>G and c.118_119insGT mutation (Cameron et al. 2011) while in fibroblasts of patient with TMEM70 g.2436-3789 in-frame deletion the swollen and irregularly shaped mitochondria with partial to complete loss of the cristae and a fragmented mitochondrial network were found (Jonckheere et al. 2011). The lack of ATP synthase dimers preventing formation of cristae may further potentiate functional defect in the synthesis of ATP, because the apical cristae structures with concentrated ribbon arrays of complex $\mathrm{V}$ appear to be associated with an increase in charge density and thus in the local $\mathrm{pH}$ gradient by approximately 0.5 units, leading to improved efficiency of ATP synthesis (Strauss et al. 2008, Davies et al. 2011).

\section{Conclusions}

Within the last ten years a substantial progress has been made in the characterization of moleculargenetic basis of ATP synthase disorders caused by mutations in nuclear genes. Improved diagnostics and genetic counseling of affected families represent an immediate outcome of this effort. However, equally significant is the new knowledge on basic mechanisms and factors involved in biosynthesis of enzyme components, their processing and assembly into native 
structure of ATP synthase complex. In contrast to energetic function of ATP synthase that is already well characterized at the molecular level, process of the mammalian enzyme biogenesis is still far from being completely understood. Analysis of inborn genetic disorders represents an invaluable tool for deciphering of the biogenetic mechanisms as well as for the development of future therapeutic strategies.

\section{Conflict of Interest}

There is no conflict of interest.

\section{Acknowledgements}

This work was supported by the Grant Agency of the
Czech Republic (P303/11/0970, P303/12/1363), the Grant Agency of the Charles University in Prague (370411), the Grant Agency of the Ministry of Health of the Czech Republic (NT12370, NT14050), and Ministry of Education, Youth and Sports of the Czech Republic (RVO:67985823).

\begin{abstract}
Abbreviations
3-MGA, 3-methylglutaconic aciduria; AA, amino acid; MILS, Maternally inherited Leigh syndrome; mtDNA, mitochondrial DNA; NARP, Neurogenic muscle weakness, ataxia, and retinitis pigmentosa; OXPHOS, oxidative phosphorylation system; ROS, reactive oxygen species.
\end{abstract}

\section{References}

ACKERMAN SH, TZAGOLOFF A: Identification of two nuclear genes (ATP11, ATP12) required for assembly of the yeast F1-ATPase. Proc Natl Acad Sci USA 87: 4986-4990, 1990.

ACKERMAN SH, TZAGOLOFF A: Function, structure, and biogenesis of mitochondrial ATP synthase. Prog Nucleic Acid Res Mol Biol 80: 95-133, 2005.

ATAY Z, BEREKET A, TURAN S, HALILOGLU B, MEMISOGLU A, KHAYAT M, SHALEV SA, SPIEGEL R: A novel homozygous TMEM70 mutation results in congenital cataract and neonatal mitochondrial encephalocardiomyopathy. Gene 515: 197-199, 2013.

BARACCA A, SGARBI G, MATTIAZZI M, CASALENA G, PAGNOTTA E, VALENTINO ML, MOGGIO M, LENAZ G, CARELLI V, SOLAINI G: Biochemical phenotypes associated with the mitochondrial ATP6 gene mutations at nt8993. Biochim Biophys Acta 1767: 913-919, 2007.

BOURGERON T, RUSTIN P, CHRETIEN D, BIRCH-MACHIN M, BOURGEOIS M, VIEGAS-PEQUIGNOT E, MUNNICH A, ROTIG A: Mutation of a nuclear succinate dehydrogenase gene results in mitochondrial respiratory chain deficiency. Nat Genet 11: 144-149, 1995.

BOYER PD: A model for conformational coupling of membrane potential and proton translocation to ATP synthesis and to active transport. FEBS Lett 58: 1-6, 1975.

CALVO S, JAIN M, XIE X, SHETH SA, CHANG B, GOLDBERGER OA, SPINAZZOLA A, ZEVIANI M, CARR SA, MOOTHA VK: Systematic identification of human mitochondrial disease genes through integrative genomics. Nat Genet 38: 576-582, 2006.

CAMERON JM, LEVANDOVSKIY V, MACKAY N, ACKERLEY C, CHITAYAT D, RAIMAN J, HALLIDAY WH, SCHULZE A, ROBINSON BH: Complex V TMEM70 deficiency results in mitochondrial nucleoid disorganization. Mitochondrion 11: 191-199, 2011.

CARROZZO R, TESSA A, VAZQUEZ-MEMIJE ME, PIEMONTE F, PATRONO C, MALANDRINI A, DIONISIVICI C, VILARINHO L, VILLANOVA M, SCHAGGER H, FEDERICO A, BERTINI E, SANTORELLI FM: The T9176G mtDNA mutation severely affects ATP production and results in Leigh syndrome. Neurology 56: 687-690, 2001.

CHEN R, RUNSWICK MJ, CARROLL J, FEARNLEY IM, WALKER JE: Association of two proteolipids of unknown function with ATP synthase from bovine heart mitochondria. FEBS Lett 581: 3145-3148, 2007.

CIZKOVA A, STRANECKY V, MAYR JA, TESAROVA M, HAVLICKOVA V, PAUL J, IVANEK R, KUSS AW, HANSIKOVA H, KAPLANOVA V, VRBACKY M, HARTMANNOVA H, NOSKOVA L, HONZIK T, DRAHOTA Z, MAGNER M, HEJZLAROVA K, SPERL W, ZEMAN J, HOUSTEK J, KMOCH S: TMEM70 mutations cause isolated ATP synthase deficiency and neonatal mitochondrial encephalocardiomyopathy. Nat Genet 40: 1288-1290, 2008. 
CRAIG K, ELLIOTT HR, KEERS SM, LAMBERT C, PYLE A, GRAVES TD, WOODWARD C, SWEENEY MG, DAVIS MB, HANNA MG, CHINNERY PF: Episodic ataxia and hemiplegia caused by the 8993T->C mitochondrial DNA mutation. J Med Genet 44: 797-799, 2007.

D'AURELIO M, VIVES-BAUZA C, DAVIDSON MM, MANFREDI G: Mitochondrial DNA background modifies the bioenergetics of NARP/MILS ATP6 mutant cells. Hum Mol Genet 19: 374-386, 2010.

DAVIES KM, STRAUSS M, DAUM B, KIEF JH, OSIEWACZ HD, RYCOVSKA A, ZICKERMANN V, KUHLBRANDT W: Macromolecular organization of ATP synthase and complex I in whole mitochondria. Proc Natl Acad Sci USA 108: 14121-14126, 2011.

De MEIRLEIR L, SENECA S, LISSENS W, DE CLERCQ I, EYSKENS F, GERLO E, SMET J, VAN COSTER R: Respiratory chain complex V deficiency due to a mutation in the assembly gene ATP12. J Med Genet 41: 120-124, 2004.

DIMAURO S: Mitochondrial diseases. Biochim Biophys Acta 1658: 80-88, 2004.

DIMAURO S: A history of mitochondrial diseases. J Inherit Metab Dis 34: 261-276, 2011.

ENNS GM, BAI RK, BECK AE, WONG LJ: Molecular-clinical correlations in a family with variable tissue mitochondrial DNA T8993G mutant load. Mol Genet Metab 88: 364-371, 2006.

HAVLICKOVA V, KAPLANOVA V, NUSKOVA H, DRAHOTA Z, HOUSTEK J: Knockdown of F1 epsilon subunit decreases mitochondrial content of ATP synthase and leads to accumulation of subunit c. Biochim Biophys Acta 1797: 1124-1129, 2010.

HAVLICKOVA KARBANOVA V, CIZKOVA VRBACKA A, HEJZLAROVA K, NUSKOVA H, STRANECKY V, POTOCKA A, KMOCH S, HOUSTEK J: Compensatory upregulation of respiratory chain complexes III and IV in isolated deficiency of ATP synthase due to TMEM70 mutation. Biochim Biophys Acta 1817: 1037-1043, 2012.

HEJZLAROVA $\mathrm{K}$, TESAROVA $\mathrm{M}$, VRBACKA-CIZKOVA A, VRBACKY M, HARTMANNOVA H, KAPLANOVA V, NOSKOVA L, KRATOCHVILOVA H, BUZKOVA J, HAVLICKOVA V, ZEMAN J, KMOCH S, HOUSTEK J: Expression and processing of the TMEM70 protein. Biochim Biophys Acta 1807: 144-149, 2011.

HOLME E, GRETER J, JACOBSON CE, LARSSON NG, LINDSTEDT S, NILSSON KO, OLDFORS A, TULINIUS M: Mitochondrial ATP-synthase deficiency in a child with 3-methylglutaconic aciduria. Pediatr Res 32: 731-735, 1992.

HOLT IJ, HARDING AE, MORGAN-HUGHES JA: Deletions of muscle mitochondrial DNA in patients with mitochondrial myopathies. Nature 331: 717-719, 1988.

HONZIK T, TESAROVA M, MAYR JA, HANSIKOVA H, JESINA P, BODAMER O, KOCH J, MAGNER M, FREISINGER P, HUEMER M, KOSTKOVA O, VAN COSTER R, KMOCH S, HOUSTEK J, SPERL W, ZEMAN J: Mitochondrial encephalocardio-myopathy with early neonatal onset due to TMEM70 mutation. Arch Dis Child 95: 296-301, 2010.

HOUSTEK J, KLEMENT P, FLORYK D, ANTONICKA H, HERMANSKA J, KALOUS M, HANSIKOVA H, HOUST'KOVA H, CHOWDHURY SK, ROSIPAL T, KMOCH S, STRATILOVA L, ZEMAN J: A novel deficiency of mitochondrial ATPase of nuclear origin. Hum Mol Genet 8: 1967-1974, 1999.

HOUSTEK J, MRACEK T, VOJTISKOVA A, ZEMAN J: Mitochondrial diseases and ATPase defects of nuclear origin. Biochim Biophys Acta 1658: 115-121, 2004.

HOUSTEK J, KMOCH S, ZEMAN J: TMEM70 protein - a novel ancillary factor of mammalian ATP synthase. Biochim Biophys Acta 1787: 529-532, 2009.

HUNG PC, WANG HS: A previously undescribed leukodystrophy in Leigh syndrome associated with T9176C mutation of the mitochondrial ATPase 6 gene. Dev Med Child Neurol 49: 65-67, 2007.

JESINA P, TESAROVA M, FORNUSKOVA D, VOJTISKOVA A, PECINA P, KAPLANOVA V, HANSIKOVA H, ZEMAN J, HOUSTEK J: Diminished synthesis of subunit a (ATP6) and altered function of ATP synthase and cytochrome c oxidase due to the mtDNA 2 bp microdeletion of TA at positions 9205 and 9206 . Biochem J 383: 561-571, 2004. 
JONCKHEERE AI, HOGEVEEN M, NIJTMANS LG, VAN DEN BRAND MA, JANSSEN AJ, DIEPSTRA JH, VAN DEN BRANDT FC, VAN DEN HEUVEL LP, HOL FA, HOFSTE TG, KAPUSTA L, DILLMANN U, SHAMDEEN MG, SMEITINK JA, RODENBURG RJ: A novel mitochondrial ATP8 gene mutation in a patient with apical hypertrophic cardiomyopathy and neuropathy. J Med Genet 45: 129-133, 2008.

JONCKHEERE AI, HUIGSLOOT M, LAMMENS M, JANSEN J, VAN DEN HEUVEL LP, SPIEKERKOETTER U, VON KLEIST-RETZOW JC, FORKINK M, KOOPMAN WJ, SZKLARCZYK R, HUYNEN MA, FRANSEN JA, SMEITINK JA, RODENBURG RJ: Restoration of complex V deficiency caused by a novel deletion in the human TMEM70 gene normalizes mitochondrial morphology. Mitochondrion 11: 954-963, 2011.

JONCKHEERE AI, SMEITINK JA, RODENBURG RJ: Mitochondrial ATP synthase: architecture, function and pathology. J Inherit Metab Dis 35: 211-225, 2012.

JONCKHEERE AI, RENKEMA GH, BRAS M, VAN DEN HEUVEL LP, HOISCHEN A, GILISSEN C, NABUURS SB, HUYNEN MA, DE VRIES MC, SMEITINK JA, RODENBURG RJ: A complex V ATP5A1 defect causes fatal neonatal mitochondrial encephalopathy. Brain 136: 1544-1554, 2013.

KARA B, ARIKAN M, MARAS H, ABACI N, CAKIRIS A, USTEK D: Whole mitochondrial genome analysis of a family with NARP/MILS caused by m.8993T>C mutation in the MT-ATP6 gene. Mol Genet Metab 107: 389-393, 2012.

KUCHARCZYK R, ZICK M, BIETENHADER M, RAK M, COUPLAN E, BLONDEL M, CAUBET SD, DI RAGO JP: Mitochondrial ATP synthase disorders: molecular mechanisms and the quest for curative therapeutic approaches. Biochim Biophys Acta 1793: 186-199, 2009.

LEFEBVRE-LEGENDRE L, VAILLIER J, BENABDELHAK H, VELOURS J, SLONIMSKI PP, DI RAGO JP: Identification of a nuclear gene (FMC1) required for the assembly/stability of yeast mitochondrial F(1)-ATPase in heat stress conditions. $J$ Biol Chem 276: 6789-6796, 2001.

LEFEBVRE-LEGENDRE L, SALIN B, SCHAEFFER J, BRETHES D, DAUTANT A, ACKERMAN SH, DI RAGO JP: Failure to assemble the alpha 3 beta 3 subcomplex of the ATP synthase leads to accumulation of the alpha and beta subunits within inclusion bodies and the loss of mitochondrial cristae in Saccharomyces cerevisiae. J Biol Chem 280: 18386-18392, 2005.

MATTIAZZI M, VIJAYVERGIYA C, GAJEWSKI CD, DEVIVO DC, LENAZ G, WIEDMANN M, MANFREDI G: The mtDNA T8993G (NARP) mutation results in an impairment of oxidative phosphorylation that can be improved by antioxidants. Hum Mol Genet 13: 869-879, 2004.

MAYR JA, PAUL J, PECINA P, KURNIK P, FORSTER H, FOTSCHL U, SPERL W, HOUSTEK J: Reduced respiratory control with ADP and changed pattern of respiratory chain enzymes as a result of selective deficiency of the mitochondrial ATP synthase. Pediatr Res 55: 988-994, 2004.

MAYR JA, HAVLICKOVA V, ZIMMERMANN F, MAGLER I, KAPLANOVA V, JESINA P, PECINOVA A, NUSKOVA H, KOCH J, SPERL W, HOUSTEK J: Mitochondrial ATP synthase deficiency due to a mutation in the ATP5E gene for the F1 epsilon subunit. Hum Mol Genet 19: 3430-3439, 2010.

MEULEMANS A, SENECA S, PRIBYL T, SMET J, ALDERWEIRLDT V, WAEYTENS A, LISSENS W, VAN COSTER R, DE MEIRLEIR L, DI RAGO JP, GATTI DL, ACKERMAN SH: Defining the pathogenesis of the human Atp12p W94R mutation using a Saccharomyces cerevisiae yeast model. J Biol Chem 285: 4099-4109, 2010.

MEYER B, WITTIG I, TRIFILIEFF E, KARAS M, SCHAGGER H: Identification of two proteins associated with mammalian ATP synthase. Mol Cell Proteomics 6: 1690-1699, 2007.

MKAOUAR-REBAI E, KAMMOUN F, CHAMKHA I, KAMMOUN N, HSAIRI I, TRIKI C, FAKHFAKH F: A de novo mutation in the adenosine triphosphatase (ATPase) 8 gene in a patient with mitochondrial disorder. J Child Neurol 25: 770-775, 2010.

MORAVA E, RODENBURG RJ, HOL F, DE VRIES M, JANSSEN A, VAN DEN HEUVEL L, NIJTMANS L, SMEITINK J: Clinical and biochemical characteristics in patients with a high mutant load of the mitochondrial T8993G/C mutations. Am J Med Genet A 140: 863-868, 2006.

MRACEK T, PECINA P, VOJTISKOVA A, KALOUS M, SEBESTA O, HOUSTEK J: Two components in pathogenic mechanism of mitochondrial ATPase deficiency: energy deprivation and ROS production. Exp Gerontol 41: 683-687, 2006. 
OHSAKAYA S, FUJIKAWA M, HISABORI T, YOSHIDA M: Knockdown of DAPIT (diabetes-associated protein in insulin-sensitive tissue) results in loss of ATP synthase in mitochondria. J Biol Chem 286: 20292-20296, 2011.

OSMAN C, WILMES C, TATSUTA T, LANGER T: Prohibitins interact genetically with Atp23, a novel processing peptidase and chaperone for the F1Fo-ATP synthase. Mol Biol Cell 18: 627-635, 2007.

PAGLIARINI DJ, CALVO SE, CHANG B, SHETH SA, VAFAI SB, ONG SE, WALFORD GA, SUGIANA C, BONEH A, CHEN WK, HILL DE, VIDAL M, EVANS JG, THORBURN DR, CARR SA, MOOTHA VK: A mitochondrial protein compendium elucidates complex I disease biology. Cell 134: 112-123, 2008.

PAUMARD P, VAILLIER J, COULARY B, SCHAEFFER J, SOUBANNIER V, MUELLER DM, BRETHES D, DI RAGO JP, VELOURS J: The ATP synthase is involved in generating mitochondrial cristae morphology. EMBO J 21: 221-230, 2002.

PITCEATHLY RD, MURPHY SM, COTTENIE E, CHALASANI A, SWEENEY MG, WOODWARD C, MUDANOHWO EE, HARGREAVES I, HEALES S, LAND J, HOLTON JL, HOULDEN H, BLAKE J, CHAMPION M, FLINTER F, ROBB SA, PAGE R, ROSE M, PALACE J, CROWE C, LONGMAN C, LUNN MP, RAHMAN S, REILLY MM, HANNA MG: Genetic dysfunction of MT-ATP6 causes axonal Charcot-Marie-Tooth disease. Neurology 79: 1145-1154, 2012.

RAK M, ZENG X, BRIERE JJ, TZAGOLOFF A: Assembly of F0 in Saccharomyces cerevisiae. Biochim Biophys Acta 1793: 108-116, 2009.

RAK M, GOKOVA S, TZAGOLOFF A: Modular assembly of yeast mitochondrial ATP synthase. EMBO $J$ 30: 920-930, 2011.

ROSSIGNOL R, MALGAT M, MAZAT JP, LETELLIER T: Threshold effect and tissue specificity. Implication for mitochondrial cytopathies. J Biol Chem 274: 33426-33432, 1999.

ROSSIGNOL R, FAUSTIN B, ROCHER C, MALGAT M, MAZAT JP, LETELLIER T: Mitochondrial threshold effects. Biochem J 370: 751-762, 2003.

RUIZ-PESINI E, LOTT MT, PROCACCIO V, POOLE JC, BRANDON MC, MISHMAR D, YI C, KREUZIGER J, BALDI P, WALLACE DC: An enhanced MITOMAP with a global mtDNA mutational phylogeny. Nucleic Acids Res 35: D823-D828, 2007.

SENECA S, ABRAMOWICZ M, LISSENS W, MULLER MF, VAMOS E, DE MEIRLEIR L: A mitochondrial DNA microdeletion in a newborn girl with transient lactic acidosis. J Inherit Metab Dis 19: 115-118, 1996.

SHCHELOCHKOV OA, LI FY, WANG J, ZHAN H, TOWBIN JA, JEFFERIES JL, WONG LJ, SCAGLIA F: Milder clinical course of Type IV 3-methylglutaconic aciduria due to a novel mutation in TMEM70. Mol Genet Metab 101: 282-285, 2010.

SHOUBRIDGE EA: Nuclear genetic defects of oxidative phosphorylation. Hum Mol Genet 10: 2277-2284, 2001.

SCHON EA, SANTRA S, PALLOTTI F, GIRVIN ME: Pathogenesis of primary defects in mitochondrial ATP synthesis. Semin Cell Dev Biol 12: 441-448, 2001.

SPERL W, JESINA P, ZEMAN J, MAYR JA, DEMEIRLEIR L, VANCOSTER R, PICKOVA A, HANSIKOVA H, HOUST'KOVA H, KREJCIK Z, KOCH J, SMET J, MUSS W, HOLME E, HOUSTEK J: Deficiency of mitochondrial ATP synthase of nuclear genetic origin. Neuromuscul Disord 16: 821-829, 2006.

SPIEGEL R, KHAYAT M, SHALEV SA, HOROVITZ Y, MANDEL H, HERSHKOVITZ E, BARGHUTI F, SHAAG A, SAADA A, KORMAN SH, ELPELEG O, YATSIV I: TMEM70 mutations are a common cause of nuclear encoded ATP synthase assembly defect: further delineation of a new syndrome. J Med Genet 48: 177-182, 2011.

STOJANOVIC V, DORONJSKI A: Mild form of 3-methylglutaconic aciduria type IV and mutation in the TMEM70 genes. J Pediatr Endocrinol Metab 26: 151-154, 2013.

STRAUSS M, HOFHAUS G, SCHRODER RR, KUHLBRANDT W: Dimer ribbons of ATP synthase shape the inner mitochondrial membrane. EMBO J 27: 1154-1160, 2008.

SYNOFZIK M, SCHICKS J, WILHELM C, BORNEMANN A, SCHOLS L: Charcot-Marie-Tooth hereditary neuropathy due to a mitochondrial ATP6 mutation. Eur J Neurol 19: e114-e116, 2012. 
TORRACO A, VERRIGNI D, RIZZA T, MESCHINI MC, VAZQUEZ-MEMIJE ME, MARTINELLI D, BIANCHI M, PIEMONTE F, DIONISI-VICI C, SANTORELLI FM, BERTINI E, CARROZZO R: TMEM70: a mutational hot spot in nuclear ATP synthase deficiency with a pivotal role in complex V biogenesis. Neurogenetics 13: 375-386, 2012

TORT F, DEL TORO M, LISSENS W, MONTOYA J, FERNANDEZ-BURRIEL M, FONT A, BUJAN N, NAVARRO-SASTRE A, LOPEZ-GALLARDO E, ARRANZ JA, RIUDOR E, BRIONES P, RIBES A: Screening for nuclear genetic defects in the ATP synthase-associated genes TMEM70, ATP12 and ATP5E in patients with 3-methylglutaconic aciduria. Clin Genet 80: 297-300, 2011.

TZAGOLOFF A, BARRIENTOS A, NEUPERT W, HERRMANN JM: Atp10p assists assembly of Atp6p into the F0 unit of the yeast mitochondrial ATPase. J Biol Chem 279: 19775-19780, 2004.

VAFAI SB, MOOTHA VK: Mitochondrial disorders as windows into an ancient organelle. Nature 491: 374-383, 2012.

VAZQUEZ-MEMIJE ME, RIZZA T, MESCHINI MC, NESTI C, SANTORELLI FM, CARROZZO R: Cellular and functional analysis of four mutations located in the mitochondrial ATPase6 gene. $J$ Cell Biochem 106: 878-886, 2009.

VERNY C, GUEGEN N, DESQUIRET V, CHEVROLLIER A, PRUNDEAN A, DUBAS F, CASSEREAU J, FERRE M, AMATI-BONNEAU P, BONNEAU D, REYNIER P, PROCACCIO V: Hereditary spastic paraplegia-like disorder due to a mitochondrial ATP6 gene point mutation. Mitochondrion 11: 70-75, 2010.

WALKER JE: The ATP synthase: the understood, the uncertain and the unknown. Biochem Soc Trans 41: 1-16, 2013.

WALlACE DC, SINGH G, LOTT MT, HODGE JA, SCHURR TG, LEZZA AM, ELSAS LJ 2ND, NIKOSKELAINEN EK: Mitochondrial DNA mutation associated with Leber's hereditary optic neuropathy. Science 242: 1427-1430, 1988.

WANG ZG, WHITE PS, ACKERMAN SH: Atp11p and Atp12p are assembly factors for the F(1)-ATPase in human mitochondria. J Biol Chem 276: 30773-30778, 2001.

WARE SM, EL-HASSAN N, KAHLER SG, ZHANG Q, MA YW, MILLER E, WONG B, SPICER RL, CRAIGEN WJ, KOZEL BA, GRANGE DK, WONG LJ: Infantile cardiomyopathy caused by a mutation in the overlapping region of mitochondrial ATPase 6 and 8 genes. J Med Genet 46: 308-314, 2009.

WITTIG I, SCHAGGER H: Structural organization of mitochondrial ATP synthase. Biochim Biophys Acta 1777: 592-598, 2008.

WITTIG I, SCHAGGER H: Supramolecular organization of ATP synthase and respiratory chain in mitochondrial membranes. Biochim Biophys Acta 1787: 672-680, 2009.

WITTIG I, VELOURS J, STUART R, SCHAGGER H: Characterization of domain interfaces in monomeric and dimeric ATP synthase. Mol Cell Proteomics 7: 995-1004, 2008.

WITTIG I, MEYER B, HEIDE H, STEGER M, BLEIER L, WUMAIER Z, KARAS M, SCHAGGER H: Assembly and oligomerization of human ATP synthase lacking mitochondrial subunits a and A6L. Biochim Biophys Acta 1797: 1004-1011, 2010.

WORTMANN SB, RODENBURG RJ, JONCKHEERE A, DE VRIES MC, HUIZING M, HELDT K, VAN DEN HEUVEL LP, WENDEL U, KLUIJTMANS LA, ENGELKE UF, WEVERS RA, SMEITINK JA, MORAVA E: Biochemical and genetic analysis of 3-methylglutaconic aciduria type IV: a diagnostic strategy. Brain 132: 136-146, 2009.

ZENG X, HOURSET A, TZAGOLOFF A: The Saccharomyces cerevisiae ATP22 gene codes for the mitochondrial ATPase subunit 6-specific translation factor. Genetics 175: 55-63, $2007 \mathrm{a}$.

ZENG X, NEUPERT W, TZAGOLOFF A: The metalloprotease encoded by ATP23 has a dual function in processing and assembly of subunit 6 of mitochondrial ATPase. Mol Biol Cell 18: 617-626, 2007b.

ZENG X, BARROS MH, SHULMAN T, TZAGOLOFF A: ATP25, a new nuclear gene of Saccharomyces cerevisiae required for expression and assembly of the Atp9p subunit of mitochondrial ATPase. Mol Biol Cell 19: $1366-1377,2008$. 